\title{
The differential activation of cardiovascular hormones across distinct stages of portal hypertension predicts clinical outcomes
}

\author{
Lukas Hartl $^{1,2} \cdot$ Mathias Jachs $^{1,2} \cdot$ Christopher Desbalmes $^{1,2} \cdot$ Dunja Schaufler $^{1,2} \cdot$ Benedikt Simbrunner $^{1,2,3}$. \\ Rafael Paternostro ${ }^{1,2}$. Philipp Schwabl ${ }^{1,2,3}$. David Josef Maria Bauer ${ }^{1,2}$. Georg Semmler ${ }^{1,2} \cdot$ Bernhard Scheiner $^{1,2}$. \\ Theresa Bucsics ${ }^{1,2}$ - Ernst Eigenbauer ${ }^{4} \cdot$ Rodrig Marculescu $^{5} \cdot$ Thomas Szekeres $^{5}$. Markus Peck-Radosavljevic ${ }^{1,2,6}$. \\ Stefan Kastl $\left.\right|^{7} \cdot$ Michael Trauner $^{1} \cdot$ Mattias Mandorfer $^{1,2} \cdot$ Thomas Reiberger $^{1,2,3}$ (i)
}

Received: 15 January 2021 / Accepted: 30 April 2021 / Published online: 21 May 2021

(c) The Author(s) 2021

\begin{abstract}
Background and aims The cardiovascular hormones renin/angiotensin/aldosterone (RAA), brain-type natriuretic peptide (BNP)and arginine-vasopressin (AVP) are key regulators of systemic circulatory homeostasis in portal hypertension (PH). We assessed (i) the activation of renin, BNP and AVP across distinct stages of PH and (ii) whether activation of these hormones correlates with clinical outcomes.

Methods Plasma levels of renin, proBNP and copeptin (AVP biomarker) were determined in 663 patients with advanced chronic liver disease (ACLD) undergoing hepatic venous pressure gradient (HVPG) measurement at the Vienna General Hospital between 11/2011 and 02/2019. We stratified for Child stage (A-C), HVPG (6-9 mmHg, 10-15 mmHg, $\geq 16 \mathrm{mmHg}$ ) and compensated vs. decompensated ACLD.

Results With increasing PH, hyperdynamic state was indicated by higher heart rates (6-9 mmHg: median 71.0 [IQR 18.0] bpm, 10-15 mmHg: 76.0 [19.0] bpm, $\geq 16$ mmHg: 80.0 [22.0] bpm; $p<0.001)$, lower mean arterial pressure $(6-9 \mathrm{mmHg}$ : 103.0 [13.5] mmHg, $10-15 \mathrm{mmHg}: 101.0$ [19.5] mmHg, $\geq 16 \mathrm{mmHg}: 99.0$ [21.0] mmHg; $p=0.032$ ) and lower serum sodium (6-9 mmHg: 139.0 [3.0] mmol/L, 10-15 mmHg: 138.0 [4.0] mmol/L, $\geq 16 \mathrm{mmHg}: 138.0$ [5.0] mmol/L; $p<0.001$ ). Across HVPG strata (6-9 mmHg vs. $10-15 \mathrm{mmHg}$ vs $\geq 16 \mathrm{mmHg})$, median plasma levels of renin (21.0 [50.5] vs. 25.1 [70.9] vs. 65.4 [219.6] $\mu \mathrm{IU} / \mathrm{mL} ; p<0.001)$, proBNP (86.1 [134.0] vs. 63.6 [118.0], vs. 132.2 [208.9] $\mathrm{pg} / \mathrm{mL} ; p=0.002)$ and copeptin (7.8 [7.7] vs. $5.6[8.0]$ vs. 10.7 [18.6] pmol/L; $p=0.024$ ) increased with severity of PH. Elevated renin levels independently predicted first hepatic decompensation (adjusted hazard ratio [aHR]: 1.69; 95\% confidence interval [95\% CI] 1.07-2.68; $p=0.025$ ) and mortality in compensated patients (aHR: 3.15; 95\% CI 1.70-5.84; $p<0.001$ ) and the overall cohort aHR: 1.42; 95\% CI 1.01-2.01; $p=0.046$ ). Elevated copeptin levels predicted mortality in decompensated patients (aHR: 5.77; 95\% CI 1.27-26.33; $p=0.024$ ) and in the overall cohort (aHR: 3.29; 95\% CI 1.36-7.95; $p=0.008$ ). ProBNP levels did not predict clinical outcomes.

Conclusions The cardiovascular hormones renin, proBNP and AVP are activated with progression of ACLD and PH. Renin activation is a risk factor for hepatic decompensation and mortality, especially in compensated patients. Increased plasma copeptin is a risk factor for mortality, in particular in decompensated patients.
\end{abstract}

Keywords Renin · Natriuretic peptide · brain · Arginine vasopressin · proBNP · Copeptin · Renin/angiotensin/aldosterone system $\cdot$ Hyperdynamic circulation $\cdot$ Cirrhosis $\cdot$ Ascites $\cdot$ Decompensation

\section{Abbreviations}

95\% CI $\quad 95 \%$ Confidence interval

ACLD Advanced chronic liver disease

Thomas Reiberger

thomas.reiberger@meduniwien.ac.at

Extended author information available on the last page of the article
ACEi/ARB Angiotensin-converting-enzyme inhibitors/ angiotensin-1-receptor blockers

aHR Adjusted hazard ratio

AVP Arginine-vasopressin

BNP Brain-type natriuretic peptide

cACLD Compensated advanced chronic liver disease

CSPH Clinically significant portal hypertension

CTP Child-Turcotte-Pugh 


$\begin{array}{ll}\text { dACLD } & \begin{array}{l}\text { Decompensated advanced chronic liver } \\ \text { disease }\end{array} \\ \text { EC } & \text { Ethics committee } \\ \text { HCC } & \text { Hepatocellular carcinoma } \\ \text { HE } & \text { Hepatic encephalopathy } \\ \text { HR } & \text { Hazard ratio } \\ \text { HVPG } & \text { Hepatic venous pressure gradient } \\ \text { IQR } & \text { Interquartile range } \\ \text { LT } & \text { Liver transplantation } \\ \text { MAP } & \text { Mean arterial pressure } \\ \text { MELD } & \text { Model for end-stage liver disease } \\ n & \text { Number } \\ \text { PH } & \text { Portal hypertension } \\ \text { proBNP } & \text { Probrain-type natriuretic peptide } \\ \text { RAA } & \text { Renin/angiotensin/aldosterone } \\ \text { SIADH } & \text { Syndrome of inappropriate antidiuretic hor- } \\ & \text { mone secretion } \\ \text { TIPS } & \text { Transjugular intrahepatic portosystemic } \\ & \text { shunt } \\ \text { VIF } & \text { Variance inflation factor } \\ \text { WHVP } & \text { Wedged hepatic venous pressure }\end{array}$

\section{Introduction}

Advanced chronic liver disease (ACLD) causes considerable morbidity and mortality word-wide [1]. Portal hypertension (PH) drives the development of hepatic decompensation and thus plays a pivotal role in ACLD progression [2-4]. Clinically, $\mathrm{PH}$ is defined as hepatic venous pressure gradient (HVPG) $\geq 6 \mathrm{mmHg}$, although PH-related complications occur mostly in patients with HVPG $\geq 10 \mathrm{mmHg}$, which denotes clinically significant $\mathrm{PH}(\mathrm{CSPH})$ [5]. Furthermore, $\mathrm{HVPG} \geq 16 \mathrm{mmHg}$ is linked to increased risk of hepatic decompensation, as well as mortality in decompensated cirrhosis [6].

PH in ACLD is caused by both increased intrahepatic vascular resistance and hyperdynamic circulation. An abundance of vasodilators results in increased inflow into the portal venous system, aggravating PH [7]. At the same time, a decrease in peripheral vascular resistance is compensated by elevated cardiac output to maintain mean arterial pressure (MAP), which also promotes splanchnic hyperemia [8].

The renin/angiotensin/aldosterone (RAA) system, braintype natriuretic peptide (BNP) and arginine-vasopressin (AVP) not only represent key regulators of circulatory homeostasis, but also play an important role in $\mathrm{PH}$ and hyperdynamic circulation [9-11]. While AVP production is primarily regulated by central osmoreceptors sensing plasma osmolality [12], BNP is released by stretching of the myocardium [13]. The regulation of renin secretion is complex, as it is triggered by a decrease in MAP (baroreceptor stimulation), a decrease of sodium concentration in the distal tubule (macula densa stimulation), or sympathetic nervous system activity (beta-1-adrenergic stimulation) [14]. In 1980, Bosch et al. showed that plasma renin activity directly correlates with wedged hepatic venous pressure (WHVP) [15], suggesting a link between RAA activation and $\mathrm{PH}$, and there is overwhelming evidence of increased levels of renin in cirrhotic patients with ascites [15-17]. Furthermore, previous studies have indicated that increased levels of renin and copeptin, an AVP biomarker, may indicate increased risk for mortality in ACLD patients [17-20]. However, these three systems of circulatory homeostasis are yet to be systematically investigated considering both the severity of liver dysfunction and of PH.

The objectives of this study were to assess the activation of renin, proBNP and AVP in distinct stages of (i) liver dysfunction, i.e. MELD/Child strata, (ii) of portal hypertension, i.e. HVPG strata, and (iii) to investigate whether alterations of these systems correlate with the risk for clinical events.

\section{Methods}

\section{Study population}

Patients with ACLD undergoing measurement of HVPG at the Vienna General Hospital between 11/2011 and 02/2019 showing PH were included. At the time of HVPG measurement, hemodynamic parameters (heart rate, MAP) were recorded and blood samples were withdrawn in supine position after the patients rested for at least $30 \mathrm{~min}$. Notably, as HVPG measurement is usually performed as an outpatient procedure, most of our patient were not hospitalized at the time of catheterization.

Patients on non-selective beta-blockers, with invalid HVPG measurements and lack of critical clinical or laboratory data were excluded. Patients after liver transplantation (LT) or transjugular intrahepatic portosystemic shunt (TIPS), with cardiac cirrhosis or hepatocellular carcinoma (HCC) out of Milan criteria were excluded.

Patients were stratified for CTP stage, for MELD 6-9, $10-15$ and $\geq 16$ points, and for HVPG $(6-9 \mathrm{mmHg}, 10-15$ $\mathrm{mmHg}, \geq 16 \mathrm{mmHg}$ ). Etiology of ACLD, comorbidities (arterial hypertension, diabetes mellitus, coronary heart disease, heart failure), age, presence of varices, HCC and concomitant medication were evaluated by chart review. Furthermore, hepatic decompensation events including (i) variceal bleeding, (ii) admission due to overt hepatic encephalopathy (HE) and (iii) development or worsening of ascites were recorded. The date of LT, death, and last follow-up was documented.

Further information on measurement of HVPG, laboratory parameters and statistical analysis is provided in the supplementary material. 


\section{Ethics}

The study was approved by the ethics committee (EC) of the Medical University of Vienna (1493/2016) and performed according to the current version of the Helsinki Declaration. Due to the retrospective design of the study the EC waived the need for informed consent.

\section{Results}

\section{ACLD study population (Table 1)}

A total number of $n=663$ patients with a median age of 56.6 [IQR 15.5] years and male predominance $(n=452 ; 68.2 \%)$ were included. 307 (46.2\%) patients had

Table 1 Patient characteristics and comparison between HVPG strata

\begin{tabular}{|c|c|c|c|c|c|}
\hline \multirow[t]{2}{*}{ Patient characteristics } & \multirow[t]{2}{*}{ All patients $(n=663)$} & \multicolumn{3}{|l|}{ HVPG } & \multirow[t]{2}{*}{$p$ value } \\
\hline & & $6-9 \mathrm{mmHg}(n=114)$ & $10-15 \mathrm{mmHg}(n=170)$ & $\geq 16 \mathrm{mmHg}(n=379)$ & \\
\hline Sex, male/female (\% male) & $452 / 211(68.2 \%)$ & $83 / 31(72.8 \%)$ & $111 / 59(65.3 \%)$ & 258/121 (68.1\%) & 0.411 \\
\hline Age, years (IQR) & $56.6(15.5)$ & $55.0(15.5)$ & $56.7(14.5)$ & $57.2(5.9)$ & 0.301 \\
\hline Etiology of CLD & & & & & $<0.001$ \\
\hline $\mathrm{ALD}, n(\%)$ & $240(36.2 \%)$ & $13(11.4 \%)$ & $52(30.6 \%)$ & $175(46.2 \%)$ & \\
\hline Viral, $n(\%)$ & $238(35.9 \%)$ & $64(56.1 \%)$ & $76(44.7 \%)$ & $98(25.9 \%)$ & \\
\hline $\mathrm{NASH}, n(\%)$ & $43(6.5 \%)$ & $6(5.3 \%)$ & $12(7.1 \%)$ & $25(6.6 \%)$ & \\
\hline Cryptogenic, $n(\%)$ & $92(13.9 \%)$ & $13(11.4 \%)$ & $19(11.2 \%)$ & $60(15.8 \%)$ & \\
\hline $\mathrm{PBC} / \mathrm{PSC}, n(\%)$ & $23(3.5 \%)$ & $9(7.9 \%)$ & $6(3.5 \%)$ & $8(2.1 \%)$ & \\
\hline $\mathrm{AIH}, n(\%)$ & $16(2.4 \%)$ & $5(4.4 \%)$ & $3(1.8 \%)$ & $8(2.1 \%)$ & \\
\hline Other, $n(\%)$ & $11(1.6 \%)$ & $4(3.5 \%)$ & $2(1.2 \%)$ & $5(1.3 \%)$ & \\
\hline MELD, median (IQR) & $11(6)$ & $9(3)$ & $10(4)$ & $12(5)$ & $<0.001$ \\
\hline Decompensated ACLD, $n(\%)$ & $356(53.7 \%)$ & $19(16.7 \%)$ & $67(39.4 \%)$ & $270(71.2 \%)$ & $<0.001$ \\
\hline Severe/refractory ascites, $n(\%)$ & $132(19.9 \%)$ & $3(2.6 \%)$ & $15(8.8 \%)$ & $76(20.1 \%)$ & $<0.001$ \\
\hline History of variceal bleeding, $n(\%)$ & $94(14.2 \%)$ & $8(7.0 \%)$ & $18(10.6 \%)$ & $106(28.0 \%)$ & $<0.001$ \\
\hline CTP score, median (IQR) & $6(4)$ & $5(1)$ & $6(2)$ & $8(3)$ & $<0.001$ \\
\hline Child-A, $n(\%)$ & $343(51.7 \%)$ & $96(84.2 \%)$ & $120(70.6 \%)$ & $127(33.5 \%)$ & $<0.001$ \\
\hline Child-B, $n(\%)$ & $211(31.8 \%)$ & $14(12.3 \%)$ & $35(20.6 \%)$ & $162(42.7 \%)$ & \\
\hline Child-C, $n(\%)$ & $109(16.5 \%)$ & $4(3.5 \%)$ & $15(8.8 \%)$ & $90(23.7 \%)$ & \\
\hline Albumin, g/L (IQR) & $36.0(8.8)$ & $40.1(5.5)$ & $38.4(7.0)$ & $33.4(7.9)$ & $<0.001$ \\
\hline Bilirubin, mg/dL (IQR) & $1.2(1.4)$ & $0.8(0.7)$ & $0.94(0.77)$ & $1.47(1.82)$ & $<0.001$ \\
\hline INR, median (IQR) & $1.3(0.3)$ & $1.2(0.3)$ & $1.2(0.3)$ & $1.3(0.3)$ & $<0.001$ \\
\hline Creatinine, mg/dL (IQR) & $0.8(0.3)$ & $0.8(0.3)$ & $0.7(0.3)$ & $0.8(0.3)$ & 0.218 \\
\hline Sodium, mmol/L (IQR) & $138.0(5.0)$ & $139.0(3.0)$ & $138.0(4.0)$ & $138.0(5.0)$ & $<0.001$ \\
\hline Intake of diuretics, $n(\%)$ & $335(50.5 \%)$ & $25(21.9 \%)$ & $69(40.6 \%)$ & $241(63.6 \%)$ & $<0.001$ \\
\hline Intake of ACEi/ARB, $n(\%)$ & $90(13.6 \%)$ & $26(22.8 \%)$ & $27(15.9 \%)$ & $37(9.8 \%)$ & 0.001 \\
\hline Arterial hypertension, $n(\%)$ & $235(35.4 \%)$ & $45(39.5 \%)$ & $64(37.6 \%)$ & $126(33.2 \%)$ & 0.317 \\
\hline Heart failure, $n(\%)$ & $31(4.7 \%)$ & $5(4.4 \%)$ & $7(4.1 \%)$ & $19(5.0 \%)$ & 0.857 \\
\hline Renin $[\mu \mathrm{IU} / \mathrm{mL}](\mathrm{IQR})$ & $37.6(148.1)$ & $21.0(50.5)$ & $25.1(70.9)$ & $65.4(219.6)$ & $<0.001$ \\
\hline Renin $>$ ULN $39.9 \mu \mathrm{IU} / \mathrm{mL}, n(\%)$ & $311(48.2 \%)$ & $37(33.0 \%)$ & $63(38.4 \%)$ & $211(57.2 \%)$ & $<0.001$ \\
\hline $\operatorname{proBNP}[\mathrm{pg} / \mathrm{mL}](\mathrm{IQR})^{\dagger}$ & $131.7(294.6)$ & $86.1(134.0)$ & $63.6(118.0)$ & $132.2(208.9)$ & 0.002 \\
\hline proBNP $>$ ULN $125.0 \mathrm{pg} / \mathrm{mL}, n(\%)^{\dagger}$ & $142(50.5 \%)$ & $17(40.5 \%)$ & $31(41.9 \%)$ & $94(57.0 \%)$ & 0.036 \\
\hline Copeptin [pmol/L] (IQR) $)^{\ddagger}$ & $10.3(21.8)$ & $7.8(7.7)$ & $5.6(8.0)$ & $10.7(18.6)$ & 0.024 \\
\hline Copeptin $>$ ULN $11.4 \mathrm{pmol} / \mathrm{L}, n(\%)^{\ddagger}$ & $62(45.6 \%)$ & $11(44.0 \%)$ & $11(31.4 \%)$ & $40(52.6 \%)$ & 0.112 \\
\hline Median follow-up, months (IQR) & $26.2(40.4)$ & & & & \\
\hline Liver transplantation, $n(\%)$ & $51(7.9 \%)$ & $4(3.5 \%)$ & $8(4.8 \%)$ & $39(10.6 \%)$ & 0.009 \\
\hline Death, $n(\%)$ & $161(24.8 \%)$ & $20(17.5 \%)$ & $35(21.1 \%)$ & $106(28.8 \%)$ & 0.015 \\
\hline Liver-related death, $n(\%)$ & $133(20.5 \%)$ & $15(13.2 \%)$ & $27(16.3 \%)$ & $91(24.7 \%)$ & 0.005 \\
\hline
\end{tabular}

$\dagger$ proBNP levels are available in 281 patients (HVPG 6-9 mmHg: 42, 10-15 mmHg: 74, $\geq 16 \mathrm{mmHg}$ : 165 )

copeptin levels are available in 136 patients (HVPG 6-9 mmHg: $25,10-15 \mathrm{mmHg}: 35, \geq 16 \mathrm{mmHg}: 76$ ) 

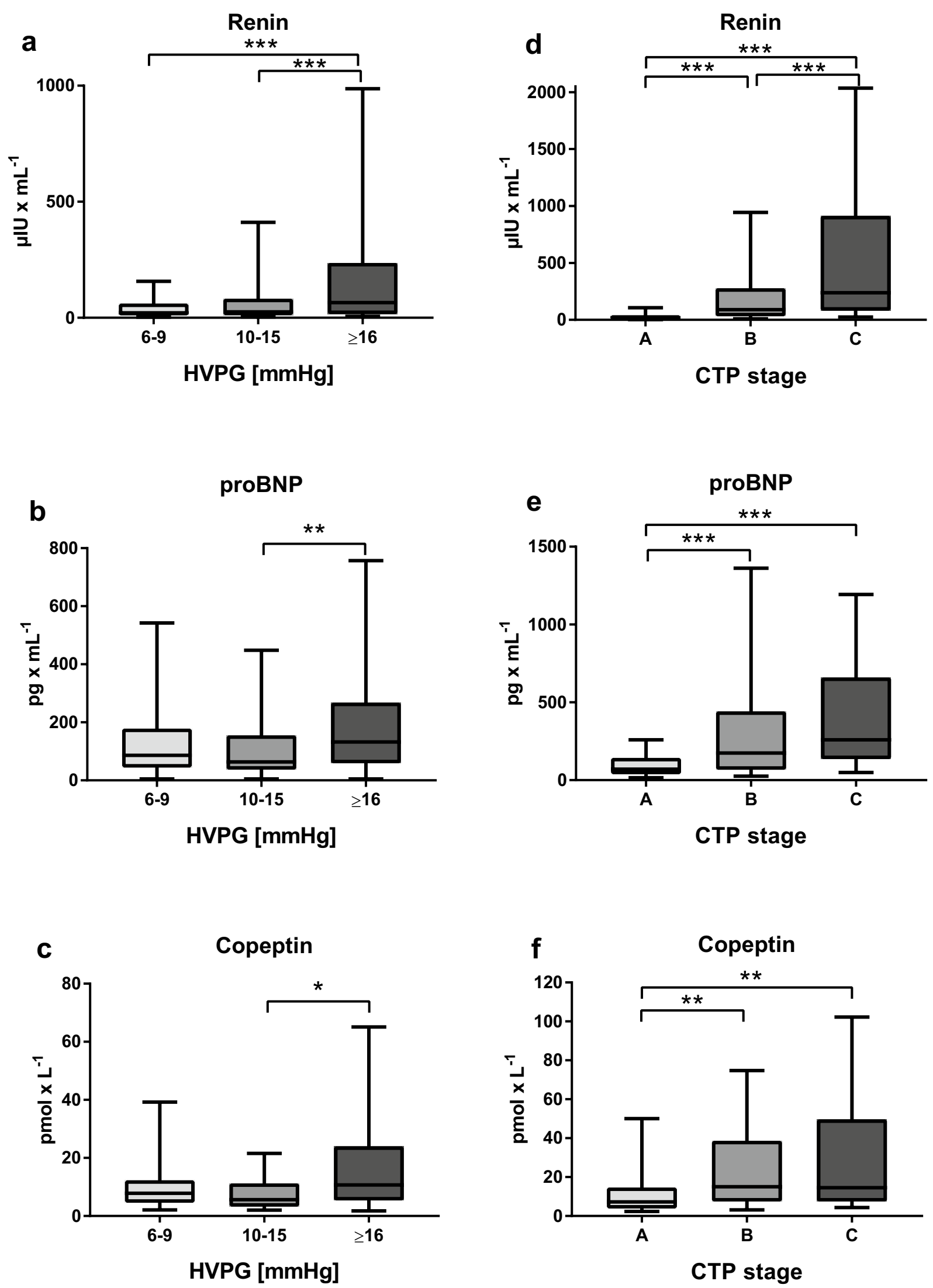
4Fig. 1 Plasma levels of renin, proBNP and copeptin stratified for HVPG $(\mathrm{a}-\mathrm{c})$ and CTP stage $(\mathrm{d}-\mathrm{f})$. $\mathrm{a}, \mathrm{d}-\mathrm{f}$ The borders of the whiskers are the 10th and the 90th percentile. b, c Depiction of plasma levels after outlier exclusion, the borders of the whiskers are the minimum and maximum. HVPG hepatic venous pressure gradient, CTP ChildTurcotte-Pugh, proBNP probrain-type natriuretic peptide; ${ }^{*} p<0.050$; $* * p<0.010 ; * * * p<0.001$

compensated (cACLD) and 356 (53.7\%) decompensated (dACLD) cirrhosis. CTP distribution was stage A in $51.7 \%(n=343), \mathrm{B}$ in $31.8 \%(n=211)$, and $\mathrm{C}$ in $16.5 \%$ $(n=109)$. Median MELD was 11 (IQR 6) points.

Stratified by severity of portal hypertension, $n=114$ (17.2\%) patients had HVPG values of 6-9 $\mathrm{mmHg}, n=170$ (25.6\%) had HVPG values of $10-15 \mathrm{mmHg}$, and $n=379$ (57.2\%) had HVPG values $\geq 16 \mathrm{mmHg}$, respectively. Notably, echocardiography was performed in 219 (33.0\%) patients. Only $4(1.8 \%)$ and $2(0.9 \%)$ patients showed moderately to highly reduced left or right ventricular dysfunction, respectively. Additional information concerning characteristics of cACLD and AACLD patients, comorbidities and concomitant medication are provided in the supplementary material.

\section{Progression of portal hypertension is paralleled by alterations in systemic hemodynamics (Fig. S1)}

With increasing severity of portal hypertension (i.e. with higher HVPG strata: $6-9 \mathrm{mmHg}$ vs. $10-15 \mathrm{mmHg}$ vs. $\geq 16$ $\mathrm{mmHg}$ ), significantly higher heart rate (median 71.0 [18.0] bpm vs. 76.0 [19.0] bpm vs. 80.0 [22.0] bpm; $p<0.001)$, lower MAP (103.0 [13.5] mmHg vs. 101.0 [19.5] mmHg vs. 99.0 [21.0] $\mathrm{mmHg} ; p=0.032$ ) and lower serum sodium levels (139.0 [3.0] mmol/L vs. 138.0 [4.0] mmol/L vs. 138.0 [5.0] $\mathrm{mmol} / \mathrm{L} ; p<0.001)$ were observed. These trends indicate a progressive state of hyperdynamic circulation with increasing severity of PH. Similar results were obtained for heart rate $(74.0$ [20.0] bpm vs. 80.0 [21.5] bpm vs. 85.0 [22.0] bpm; $p<0.001)$, MAP (105.0 [18.0] mmHg vs. 98.0 [20.0] mmHg vs. 91.0 [19.0] mmHg; $p<0.001)$ and serum sodium levels (139.0 [3.0] mmol/L vs. 137.0 [5.8] mmol/L vs. 135.0 [7.0] mmol/L, $p<0.001)$ when stratifying by CTP stages (A vs. B vs. C, respectively). HVPG did not correlate with ejection fraction $(n=216 ; p=0.548)$ or inferior vena cava (IVC) diameter $(n=64 ; p=0.412)$.

\section{Association of the severity of portal hypertension with renin, proBNP and copeptin levels (Fig. 1)}

The median renin $(n=645)$ level was 37.6 [148.9] $\mu \mathrm{IU} / \mathrm{mL}$, median proBNP $(n=281)$ level was 131.7 [294.6] $\mathrm{pg} / \mathrm{mL}$ and median copeptin $(n=136)$ level was 10.3 [21.8] pmol/L. Of note, these levels were mostly within the reported normal ranges for renin at $<39.9 \mu \mathrm{IU} / \mathrm{mL}$, for proBNP at $<125$ $\mathrm{pg} / \mathrm{mL}$, and under the determined threshold for copeptin at $<11.4 \mathrm{pmol} / \mathrm{L}$.

Renin levels (6-9 mmHg: 21.0 [50.5] $\mu \mathrm{IU} / \mathrm{mL}$ vs. 10-15 mmHg: 25.1 [70.9] $\mu \mathrm{IU} / \mathrm{mL}$ vs. $\geq 16$ mmHg: 65.4 [219.6] $\mu \mathrm{IU} / \mathrm{mL}, p<0.001)$ gradually and significantly increased with HVPG. However, there was no significant difference in renin levels between the HVPG 6-9 mmHg and the HVPG 10-15 mmHg groups.

Median plasma levels of proBNP (6-9 $\mathrm{mmHg}$ : 86.1 [134.0] pg/mL vs. $10-15 \mathrm{mmHg}: 63.6$ [118.0] $\mathrm{pg} / \mathrm{mL}$ vs. $\geq 16 \mathrm{mmHg}: 132.2$ [208.9] pg/mL; $p=0.002$ ) and copeptin (6-9 mmHg: 7.8 [7.7] pmol/L vs. $10-15 \mathrm{mmHg}: 5.6$ [8.0] pmol/L vs. $\geq 16 \mathrm{mmHg}: 10.7$ [18.6] pmol/L, $p=0.024$ ) increased with severity of $\mathrm{PH}$-although the findings were not very consistent for both proBNP and copeptin, and significant increases were only observed in the $\mathrm{HVPG} \geq 16$ mmHg vs. HVPG $10-15 \mathrm{mmHg}$ strata.

\section{Biomarkers of circulatory homeostasis across Child stages and MELD strata (Fig. 1), in hyponatremia and hypotension (Fig. S2)}

Hepatic dysfunction impacted on all three main parameters, as plasma levels of renin (Child-A: 17.7 [31.4] $\mu \mathrm{IU} /$ mL vs. B: 89.8 [245.2] $\mu \mathrm{IU} / \mathrm{mL}$ vs. C: 238.0 [833.1] $\mu \mathrm{IU} /$ $\mathrm{mL}, p<0.001$ ), proBNP (Child-A: 70.3 [105.7] pg/mL vs. B: 174.5 [375.6] pg/mL vs. C: 259.2 [524.6] pg/mL, $p<0.001$ ), as well as copeptin (CTP A: $7.3[10.8] \mathrm{pmol} / \mathrm{L}$ vs. B: 15.1 [31.2] pmol/L vs. C: 14.5 [42.1] pmol/L, $p<0.001)$ increased significantly with CTP stage. The same results were obtained when stratifying for MELD: Renin (6-9: 20.6 [45.0] $\mu \mathrm{IU} / \mathrm{mL}$ vs. 10-15: 40.3 [176.6] $\mu \mathrm{IU} / \mathrm{mL}$ vs. $\geq 16: 147.2[476.2] \mu \mathrm{IU} / \mathrm{mL} ; p<0.001)$, proBNP (6-9: 86.1 [109.2] pg/mL vs. 10-15: 133.2 [273.8] pg/mL vs. 283.9 [700.8] pg/mL; $p<0.001)$ and copeptin levels (6-9: 7.3 [9.5] pmol/L vs. 10-15: 9.4 [16.2] pmol/L vs. $\geq 16: 27.1$ [42.6] pmol/L; $p<0.001)$ increased throughout the strata.

In patients with hyponatremia $<130 \mathrm{mmol} / \mathrm{L}$, significantly elevated levels of renin $(<130 \mathrm{mmol} / \mathrm{L}: 1283.0$ [2204.2] $\mu \mathrm{IU} / \mathrm{mL}$ vs. $\geq 130 \mathrm{mmol} / \mathrm{L}: 34.6$ [120.0] $\mu \mathrm{IU} /$ $\mathrm{mL}, p<0.001)$ and copeptin $(<130 \mathrm{mmol} / \mathrm{L}: 32.3$ [19.2] pmol/L vs. $\geq 130 \mathrm{mmol} / \mathrm{L}: 9.9$ [17.3] pmol/L, $p=0.023$ ) were recorded, while there was no significant difference in plasma levels of proBNP (<130 mmol/L: 156.0 [302.4] $\mathrm{pg} / \mathrm{mL}$ vs. $\geq 130 \mathrm{mmol} / \mathrm{L}: 129.0$ [289.9] pg/mL, $p=0.797$ ) (Fig. S2). Patients with arterial hypotension, as defined by a MAP $<82 \mathrm{mmHg}$, exhibited increased plasma levels of renin (<82 mmHg: 124.7 [326.9] $\mu \mathrm{IU} / \mathrm{mL}$ vs. $\geq 82 \mathrm{mmHg}$ : 32.4 [121.6] $\mu \mathrm{IU} / \mathrm{mL}, p<0.001)$ and $\operatorname{proBNP}(<82 \mathrm{mmHg}$ : 151.7 [236.1] pg/mL vs. $\geq 82$ mmHg: 94.7 [181.8] pg/mL, $p=0.044$ ), whereas there was no significant difference in 
plasma levels of copeptin (<82 mmHg: 12.4 [20.1] pmol/L vs. $\geq 82 \mathrm{mmHg}: 10.0$ [21.9] pmol/L, $p=0.748$ ).

\section{Analysis of independent determinants of renin, proBNP and copeptin levels in ACLD patients (Table 2)}

Multivariate analysis showed that plasma levels of renin were independently correlated with hepatic dysfunction (MELD [points; B: 19.4; $p=0.020$ ]), HVPG (mmHg; B: 12.8; $p=0.015 / \mathrm{B}: 13.6 ; p=0.005)$ and serum sodium $(\mathrm{mmol} / \mathrm{L} ; \mathrm{B}:-87.2 ; p<0.001 / \mathrm{B}:-86.5 ; p<0.001)$. Plasma levels of proBNP were independently linked to hepatic dysfunction (MELD [points; B: 113.2; $p<0.001$ ], CTP score [points; B: $137.5 ; p<0.001$ ] $)$ and creatinine $(\mathrm{mg} / \mathrm{dL}$; B: 794.8; $p<0.001$ ). Finally, copeptin plasma levels were independently correlated with liver dysfunction (MELD [points; B: $1.8 ; p=0.008])$, creatinine (mg/dL; B: $17.0 ; p<0.001)$ and serum sodium $(\mathrm{mmol} / \mathrm{L} ; \mathrm{B}:-1.9 ; p=0.030)$. Independent determinants of renin, proBNP and copeptin levels in cACLD and dACLD are depicted in supplementary Tables S5 and S6.

\section{Impact of renin, proBNP and copeptin on the risk of hepatic decompensation and mortality in CACLD and dACLD (Fig. 2; Table 3)}

Follow-up data were available in 648 (cACLD: $n=302$; dACLD: $n=346$ ) patients. Median follow-up time was 26.2 [40.4] months. In total, 225 (34.7\%) patients had at least one event of hepatic decompensation during follow-up (70 patients with variceal bleeding, 70 with overt $\mathrm{HE}$ and 176 with ascites-related complications; Fig. S3).
Eighty-nine (29.5\%) cACLD patients experienced first hepatic decompensation during follow-up (12 variceal bleedings, seven episodes of overt HE and 70 occurrences of ascites). Time to first decompensation was shorter in cACLD patients with elevated renin levels ( $n=64 / 294$; $p=0.096)$, while there was no difference between patients with elevated $(n=29 / 105)$ and non-elevated proBNP plasma levels $(p=0.755)$. Importantly, cACLD patients with elevated plasma levels of copeptin $(n=17 / 55$; $p=0.024$ ) had significantly higher risk of first hepatic decompensation. Cox regression analysis adjusted for age, MELD, HVPG and albumin revealed that elevated plasma level of renin (>39.9 $\mu \mathrm{IU} / \mathrm{mL}$; hazard ratio [HR]: 1.69; 95\% confidence interval [95\% CI] $1.07-2.68 ; p=0.025$ ) independently predicted first hepatic decompensation, while there was a trend for elevated copeptin levels $(>11.4$ pmol/L; HR: 2.69; 95\% CI 0.99-7.33; $p=0.053)$. In contrast, patients with elevated proBNP plasma levels $(>125$ pg/mL; HR: 0.75 ; 95\% CI 0.36-1.56; $p=0.433$ ) were not at a higher risk for first hepatic decompensation.

Further decompensation occurred in 134 (38.6\%) dACLD patients (34 variceal bleedings, 28 admissions due to overt HE and 72 worsening of ascites events). In dACLD patients, elevated proBNP $(n=110 / 172 ; p=0.012)$ and copeptin levels $(n=45 / 77 ; p=0.014)$ were associated with significantly shorter time to further decompensation, while there was no difference in time to further decompensation between dACLD patients with elevated $(n=242 / 336)$ and non-elevated plasma levels of renin $(p=0.171)$. Neither increased renin (HR: 1.03 ; 95\% CI $0.73-1.46 ; p=0.850$ ) or proBNP (HR: $1.34 ; 95 \%$ CI $0.81-2.21 ; p=0.260$ ), nor copeptin levels (HR: 2.06; 95\% CI 0.84-5.07; $p=0.117$ )

Table 2 Assessment of independent determinants of plasma levels of (a) renin, (b) proBNP and (c) copeptin by multiple linear regression analysis ([i] model including MELD and albumin; [ii] model including CTP score and creatinine)

\begin{tabular}{|c|c|c|c|c|c|c|c|c|c|c|c|c|}
\hline & \multicolumn{4}{|c|}{ (a) Renin $(n=645)$} & \multicolumn{4}{|c|}{ (b) $\operatorname{proBNP}(n=281)$} & \multicolumn{4}{|c|}{ (c) Copeptin $(n=136)$} \\
\hline & \multicolumn{2}{|l|}{ (i) } & \multicolumn{2}{|l|}{ (ii) } & \multicolumn{2}{|l|}{ (i) } & \multicolumn{2}{|l|}{ (ii) } & \multicolumn{2}{|l|}{ (i) } & \multicolumn{2}{|l|}{ (ii) } \\
\hline & $\mathrm{aB}$ & $p$ & $\mathrm{aB}$ & $p$ & $\mathrm{aB}$ & $p$ & $\mathrm{aB}$ & $p$ & $\mathrm{aB}$ & $p$ & $\mathrm{aB}$ & $p$ \\
\hline Age, 10 years & - & - & - & - & - & - & - & - & - & - & - & - \\
\hline Sex (male) & - & - & - & - & - & - & - & - & 18.9 & 0.081 & 13.3 & 0.208 \\
\hline MELD, points & 19.4 & 0.020 & - & - & 113.2 & $<0.001$ & - & - & 1.8 & 0.008 & - & - \\
\hline CTP score, points & - & - & 10.3 & 0.571 & - & - & 137.5 & $<0.001$ & - & - & - & - \\
\hline HVPG, mmHg & 12.8 & 0.015 & 13.6 & 0.005 & - & - & - & - & - & - & - & - \\
\hline Albumin, $g / L$ & 10.5 & 0.088 & - & - & 12.9 & 0.421 & - & - & -0.3 & 0.712 & - & - \\
\hline Creatinine, $\mathrm{mg} / \mathrm{dL}$ & - & - & 279.1 & 0.054 & - & - & 794.8 & $<0.001$ & - & - & 17.0 & $<0.001$ \\
\hline Sodium, $\mathrm{mmol} / \mathrm{L}$ & -87.2 & $<0.001$ & -86.5 & $<0.001$ & - & - & - & - & -1.5 & 0.118 & -1.9 & 0.030 \\
\hline Arterial hypertension, yes & - & - & - & - & - & - & - & - & - & - & - & - \\
\hline Diabetes mellitus, yes & - & - & - & - & - & - & - & - & - & - & - & - \\
\hline Coronary heart disease, yes & - & - & - & - & - & - & - & - & - & - & - & - \\
\hline Heart failure, yes & - & - & - & - & - & - & - & - & - & - & - & - \\
\hline
\end{tabular}


predicted further decompensation after adjusting for age, MELD, HVPG and albumin.

\section{Transplant-free survival according to increased levels of renin, proBNP and copeptin (Fig. 3; Table 4)}

Fifty-one (7.9\%; cACLD: 19 [6.2\%]; dACLD: 32 [9.2\%]; $p=0.189)$ patients underwent LT and 161 (24.8\%; cACLD: 49 [16.2\%]; dACLD: 112 [32.4\%]; $p<0.001)$ patients died during follow-up with 133 (20.5\%; cACLD: 37 [12.2\%]; dACLD: $96[27.7 \%] ; p<0.001)$ deaths being attributed to liver-related complications (i.e. liver-related mortality).

Elevated levels of renin $(n=306 / 630 ; p<0.001)$, proBNP $(n=139 / 277 ; p=0.004)$ and copeptin $(n=62 / 132 ; p=0.006)$ were associated with shorter transplant-free survival. Univariate analyses showed that increased renin (HR: 2.16; 95\% CI 1.57-2.98; $p<0.001$ ), proBNP (HR: 2.03; 95\% CI 1.24-3.33; $p=0.005$ ), and copeptin levels (HR: 3.18 ; 95\% CI 1.32-7.67; $p=0.010)$ predicted mortality. After adjusting for age, sex, MELD, HVPG, albumin, sodium and HCC before baseline, renin (aHR 1.42; 95\% CI 1.01-2.01; $p=0.046$ ) and copeptin (aHR: 3.29 ; 95\% CI 1.36-7.95; $p=0.008$ ) remained as independent predictors of mortality.

Interestingly, within the cACLD cohort, elevated renin plasma levels $(n=64 / 294 ; p<0.001)$, but not elevated proBNP $(n=29 / 105 ; p=0.199)$ or copeptin levels $(n=17 / 55$; $p=0.225$ ), were associated with decreased transplant-free survival. Correspondingly, elevated plasma renin independently predicted mortality in cACLD patients adjusted for age, MELD, albumin and HCC before baseline (aHR: 3.15, 95\% CI $1.70-5.84 ; p<0.001$ ), in contrast to elevated proBNP (aHR: $1.02 ; 95 \%$ CI $0.68-1.52 ; p=0.943$ ) and copeptin levels (aHR: $2.44 ; 95 \%$ CI $0.59-10.14 ; p=0.221)$.

In the dACLD cohort, transplant-free survival was not significantly different between patients with normal vs. elevated renin $(n=242 / 346 ; p=0.650)$ nor with normal vs. elevated proBNP levels $(n=110 / 175 ; p=0.137)$. In contrast, increased copeptin levels $(n=45 / 80 ; p=0.009)$ were significantly associated with shorter transplant-free survival. In multivariate Cox regression analysis adjusted for age, MELD, HVPG and albumin, elevated copeptin remained as independent predictor for mortality in dACLD patients (aHR: 5.77; 95\% CI 1.27-26.33; $p=0.024)$. There were no independent associations between increased mortality and elevated renin (aHR: 0.89; 95\% CI $0.58-1.35 ; p=0.567$ ) or proBNP levels (aHR: $1.10 ; 95 \% \mathrm{CI}$ $0.57-2.15 ; p=0.772)$ in the dACLD cohort.

\section{Discussion}

In our thoroughly characterized cohort of ACLD patients, we observed progressive hemodynamic alterations with increasing severity of PH. Stratifying our population not only by hepatic dysfunction (by Child stage and MELD), but also for portal pressure (by the diagnostic gold-standard HVPG), we were able to evaluate the activation of key cardiovascular hormones across the full spectrum of ACLD severity. Renin, proBNP and copeptin levels all increased with severity of $\mathrm{PH}$, indicating activation of all three cardiovascular hormonal systems induced by $\mathrm{PH}$-associated systemic hemodynamic alterations. Notably, the increase of these parameters between patients with HVPG 6-9 mmHg vs. $10-15 \mathrm{mmHg}$ was not significant, suggesting that only pronounced stages of $\mathrm{PH}$ have a clinically relevant impact on the RAA, proBNP and AVP pathways. This confirms and goes beyond the findings of Bosch et al. and Arroyo et al. $[15,20]$, who showed correlations of renin activity and WHVP. It is also in line with previous studies that showed elevated plasma levels of renin, proBNP and copeptin particularly in cirrhotic patients with ascites or other PH-related complications [18, 21, 22]. Considering the implications of RAA activation in the pathogenesis of ascites, these findings explain why HVPG-values $\geq 16 \mathrm{mmHg}$ identify cACLD patients at a particularly high risk for hepatic decompensation $[6,23]$. Moreover, renin, proBNP and copeptin levels increased throughout CTP stages and MELD strata, underlining the close correlation of these parameters with the degree of hepatic dysfunction [17, 18, 22]. While there was no correlation of ejection fraction or IVC diameter with severity of portal hypertension, future studies should investigate how changes of the splanchnic/systemic circulation that are primarily caused by portal hypertension, may affect cardiac dysfunction in patients with cirrhosis.

\section{Renin}

Plasma renin levels were significantly increased in patients with arterial hypotension and hyponatremia and renin was independently associated with serum sodium concentration, suggesting renin release upon impaired kidney perfusion or due to reduced sodium concentration sensed by the macula densa [14]. Moreover, renin levels correlated with HVPG, which affirms the association between plasma renin levels and the severity of PH. It has been reported that RAA activation plays a major role in the development of the hemodynamic alterations observed in cirrhotic patients with ascites [21, 24]. However, there is also evidence that RAA is mechanistically involved in splanchnic vasodilation and increased intrahepatic resistance already in early stages of fibrosis and $\mathrm{PH}$ [21].

Importantly, cACLD patients with elevated renin plasma levels experienced first hepatic decompensation earlier with plasma renin levels being an independent predictor of first hepatic decompensation, while such an association was not found for further decompensation/ death in more advanced dACLD patients. Elevated plasma 


\section{CACLD}
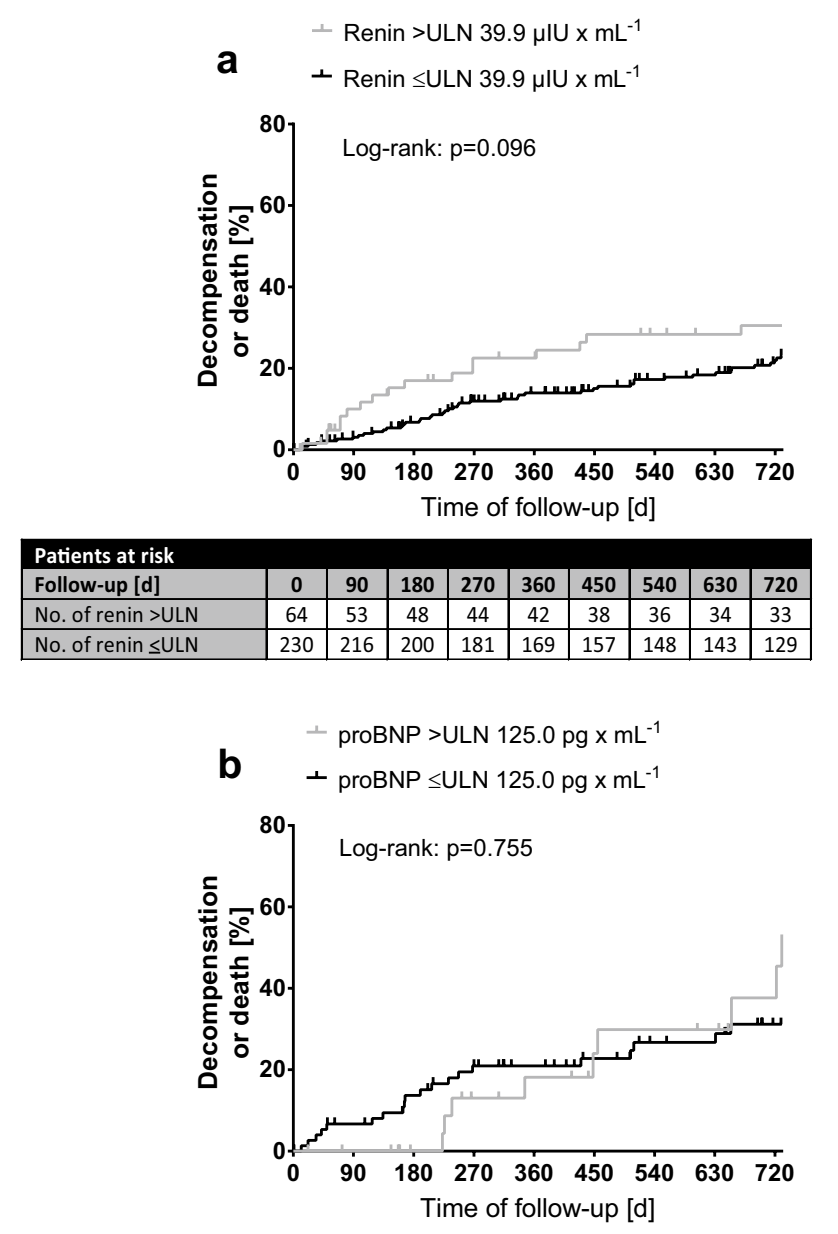

\section{dACLD}

$$
\begin{aligned}
\text { d } \quad & \quad \text { Renin }>\mathrm{ULN} 39.9 \mu \mathrm{lU} \times \mathrm{mL}^{-1} \\
& + \text { Renin } \leq \mathrm{ULN} 39.9 \mu \mathrm{IU} \times \mathrm{mL}^{-1}
\end{aligned}
$$

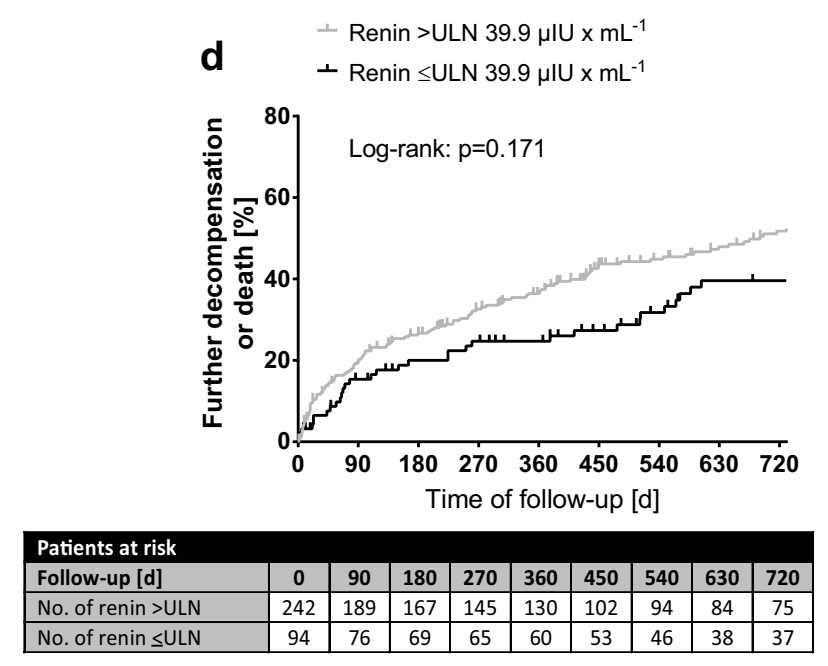

\begin{tabular}{|l|c|c|c|c|c|c|c|c|c|}
\hline Patients at risk \\
\hline Follow-up [d] & $\mathbf{0}$ & $\mathbf{9 0}$ & $\mathbf{1 8 0}$ & $\mathbf{2 7 0}$ & $\mathbf{3 6 0}$ & $\mathbf{4 5 0}$ & $\mathbf{5 4 0}$ & $\mathbf{6 3 0}$ & $\mathbf{7 2 0}$ \\
\hline No. of renin >ULN & 242 & 189 & 167 & 145 & 130 & 102 & 94 & 84 & 75 \\
\hline No. of renin $\leq \mathrm{ULN}$ & 94 & 76 & 69 & 65 & 60 & 53 & 46 & 38 & 37 \\
\hline
\end{tabular}

$$
\begin{aligned}
& \quad+\text { proBNP }>\text { ULN } 125.0 \mathrm{pg} \mathrm{x} \mathrm{mL}^{-1} \\
& \text { e } \quad \perp \text { proBNP } \leq \text { ULN } 125.0 \mathrm{pg} \mathrm{x} \mathrm{mL}^{-1}
\end{aligned}
$$

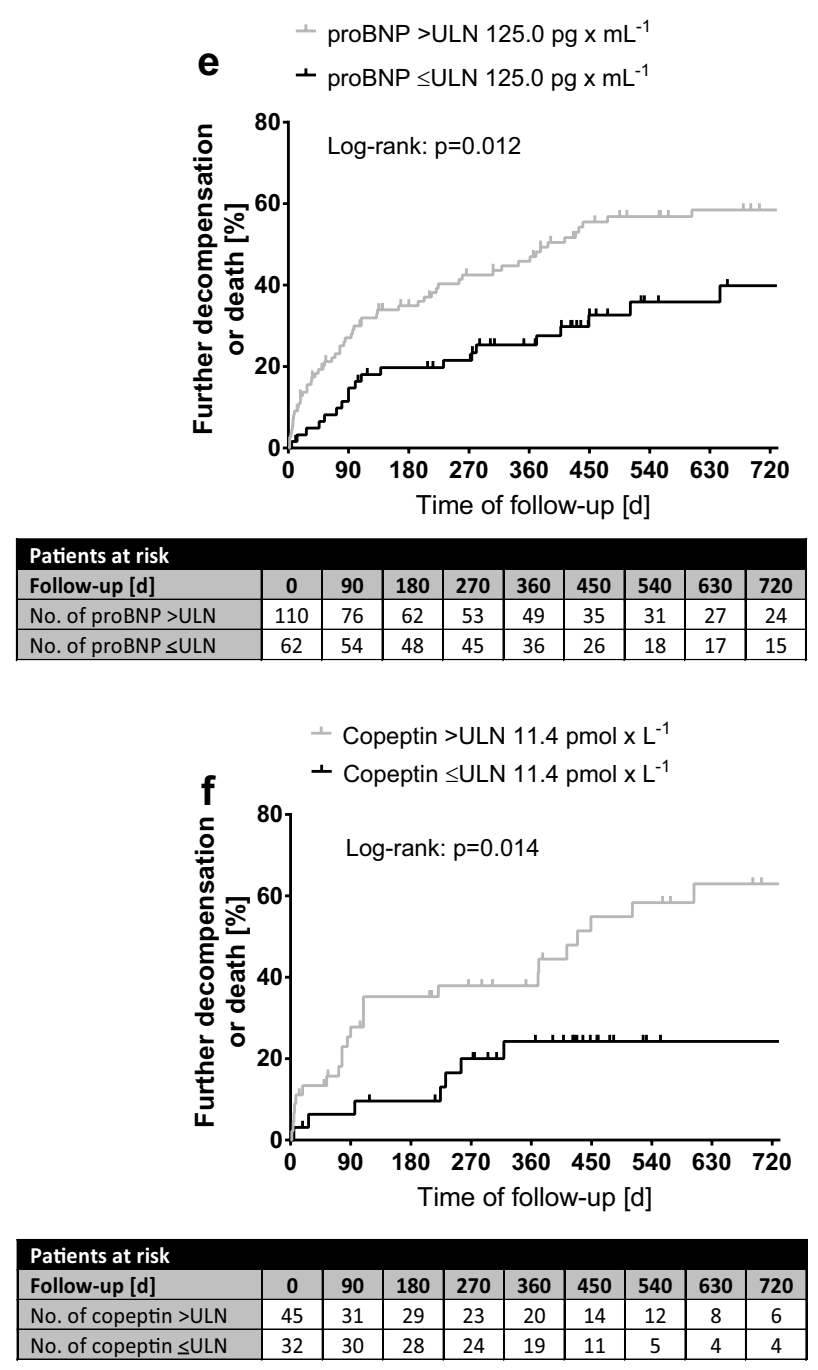

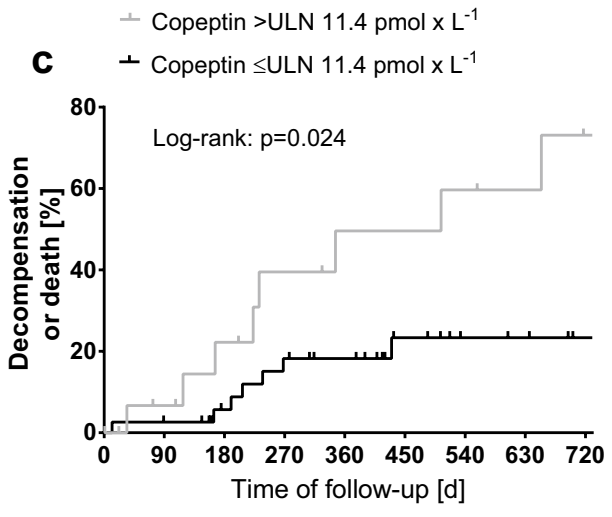

Patients at risk

Follow-up [d]

No. of copeptin $>$ ULN

No. of copeptin $\leq U L N$

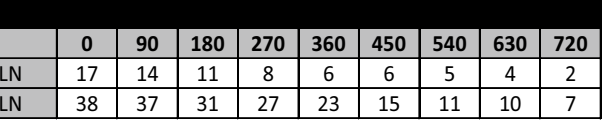


४Fig. 2 Incidence of first decompensation in a-c cACLD patients binary for elevated/non-elevated renin, proBNP and copeptin plasma levels. $\mathbf{d}-\mathbf{f}$ Incidence of further decompensation in dACLD patients. Time to any first/further decompensation event (development/worsening of ascites or HE, or development of variceal bleeding), death or end of follow-up. Log-rank test is used to determine differences between the groups. proBNP probrain-type natriuretic peptide, $U L N$ upper limit of normal

renin levels were also associated with shorter transplantfree survival and predicted mortality in CACLD, as well as in the overall cohort on adjusted Cox regression analysis. Notably, patients in the cACLD cohort were strictly compensated without (previous) ascites or ascites-related intake of diuretics. These findings are of clinical relevance, as they extend beyond findings of previous studies that reported increased plasma renin levels mostly in patients with ascites $[15,17,25]$. While most $(78.2 \%)$ of our cACLD cohort had renin levels within the physiological range, our data suggest that a pathological RAA activation may already occur in compensated patients with $\mathrm{PH}$, which is also paralleled by an increased risk for hepatic decompensation and mortality. Since RAA blockade is safe in compensated Child-A patients [26] and also seems to be particularly effective at lowering portal pressure in early ACLD stages [27], the use of RAA biomarkers may identify subgroups of patients, who particularly benefit from RAA blockade.

\section{Natriuretic peptide proBNP}

ProBNP levels increased with advanced liver dysfunction and in pronounced $\mathrm{PH}$ (HVPG $\geq 16 \mathrm{mmHg}$ ). Increased proBNP levels may indicate a hyperdynamic state in ACLD patients, as they are associated with arterial hypotension and creatinine, potentially linking proBNP to kidney dysfunction. This finding may explain, why elevated proBNP was associated with further decompensation and/or death in already decompensated ACLD patients, although its natriuretic and diuretic functions [13] should actually be beneficial in hyperdynamic ACLD patients by counteracting volume overload. Kidney dysfunction may trigger proBNP secretion through associated volume overload [28], with BNP being insufficient to overcome this volume overload in this particular setting of $\mathrm{PH}$-associated renal dysfunction. Future studies should specifically address the value of proBNP levels in assessing cardiac dysfunction and subsequent renal hypoperfusion and/or acute kidney injury in patients with dACLD. Finally, proBNP levels could also be indicative of cirrhotic cardiomyopathy [29], which is supported by an association

Table 3 Independent risk factors for first decompensation in cACLD and for further decompensation in dACLD patients

\begin{tabular}{|c|c|c|c|c|c|c|c|c|c|c|c|c|}
\hline \multirow[t]{2}{*}{ cACLD } & \multicolumn{3}{|l|}{ (i) } & \multicolumn{3}{|c|}{ (ii) Renin $(n=294)$} & \multicolumn{3}{|c|}{ (iii) $\operatorname{proBNP}(n=105)$} & \multicolumn{3}{|c|}{ (iv) Copeptin $(n=55)$} \\
\hline & HR & $95 \% \mathrm{CI}$ & $p$ & aHR & $95 \% \mathrm{CI}$ & $p$ & aHR & $95 \% \mathrm{CI}$ & $p$ & aHR & $95 \% \mathrm{CI}$ & $p$ \\
\hline enin, > ULN $39.9 \mu \mathrm{IU} / \mathrm{mL}$ & 1.46 & $0.93-2.28$ & 0.098 & 1.69 & $1.07-2.68$ & 0.025 & - & - & - & - & - & - \\
\hline proBNP, > ULN $125.0 \mathrm{pg} / \mathrm{mL}$ & 0.89 & $0.44-1.81$ & 0.755 & - & - & - & 0.75 & $0.36-1.56$ & 0.433 & - & - & - \\
\hline Copeptin, > ULN 11.4 pmol/L & 2.95 & $1.10-7.90$ & 0.031 & - & - & - & - & - & - & 2.69 & $0.99-7.33$ & 0.053 \\
\hline Age, 10 years & 1.27 & $1.07-1.50$ & 0.005 & 1.31 & $1.11-1.55$ & 0.002 & 1.09 & $0.82-1.45$ & 0.544 & 1.11 & $0.77-1.60$ & 0.588 \\
\hline Sex (male) & 0.92 & $0.61-1.37$ & 0.674 & - & - & - & - & - & - & - & - & - \\
\hline MELD, points & 1.13 & $1.08-1.19$ & $<0.001$ & 1.10 & $1.03-1.17$ & 0.003 & 1.16 & $1.05-1.29$ & 0.004 & 1.13 & $0.99-1.29$ & 0.067 \\
\hline HVPG, mmHg & 1.07 & $1.03-1.10$ & $<0.001$ & 1.06 & $1.02-1.10$ & 0.005 & 0.97 & $0.90-1.05$ & 0.461 & 0.952 & $0.86-1.05$ & 0.336 \\
\hline Albumin, g/L & 0.91 & $0.88-0.95$ & $<0.001$ & 0.95 & $0.90-1.00$ & 0.017 & 0.96 & $0.89-1.03$ & 0.276 & 0.92 & $0.81-1.04$ & 0.190 \\
\hline Sodium, mmol/L & 0.95 & 0.90 & 0.116 & - & - & - & - & - & - & - & - & - \\
\hline \multirow[t]{2}{*}{ dACLD } & \multicolumn{3}{|l|}{ (i) } & \multicolumn{3}{|c|}{ (ii) Renin $(n=336)$} & \multicolumn{3}{|c|}{ (iii) $\operatorname{proBNP}(n=172)$} & \multicolumn{3}{|c|}{ (iv) Copeptin $(n=77)$} \\
\hline & HR & $95 \% \mathrm{CI}$ & $p$ & aHR & $95 \% \mathrm{CI}$ & $p$ & aHR & $95 \% \mathrm{CI}$ & $p$ & aHR & $95 \% \mathrm{CI}$ & $p$ \\
\hline Renin, > ULN $39.9 \mu \mathrm{IU} / \mathrm{mL}$ & 1.27 & $0.90-1.77$ & 0.172 & 1.03 & $0.73-1.46$ & 0.850 & - & - & - & - & - & - \\
\hline proBNP, > ULN $125.0 \mathrm{pg} / \mathrm{mL}$ & 1.83 & $1.13-2.95$ & 0.013 & - & - & - & 1.34 & $0.81-2.21$ & 0.260 & - & - & - \\
\hline Copeptin, > ULN 11.4 pmol/L & 2.76 & $1.18-6.44$ & 0.019 & - & - & - & - & - & - & 2.06 & $0.84-5.07$ & 0.117 \\
\hline Age, 10 years & 1.21 & $1.06-1.37$ & 0.005 & 1.24 & $1.08-1.42$ & 0.003 & 1.33 & $1.09-1.62$ & 0.006 & 1.378 & $0.99-1.91$ & 0.056 \\
\hline Sex (male) & 1.28 & $0.92-1.77$ & 0.144 & - & - & - & - & - & - & - & - & - \\
\hline MELD, points & 1.06 & $1.03-1.09$ & $<0.001$ & 1.05 & $1.02-1.09$ & 0.005 & 1.08 & $1.04-1.12$ & $<0.001$ & 1.14 & $1.08-1.21$ & $<0.001$ \\
\hline HVPG, mmHg & 1.04 & $1.02-1.06$ & $<0.001$ & 1.03 & $1.01-1.05$ & 0.001 & 1.03 & $1.00-1.05$ & 0.028 & 1.01 & $0.97-1.04$ & 0.780 \\
\hline Albumin, g/L & 0.96 & $0.94-0.98$ & $<0.001$ & 0.98 & $0.96-1.00$ & 0.063 & 0.99 & $0.96-1.03$ & 0.719 & 0.98 & $0.92-1.04$ & 0.449 \\
\hline Sodium, mmol/L & 0.98 & $0.95-1.01$ & 0.212 & - & - & - & - & - & - & - & - & - \\
\hline
\end{tabular}

Next to the univariate analysis (i), multivariate cox regression models for (ii) renin, (iii) proBNP and (iv) copeptin are shown 


\section{ACLD}

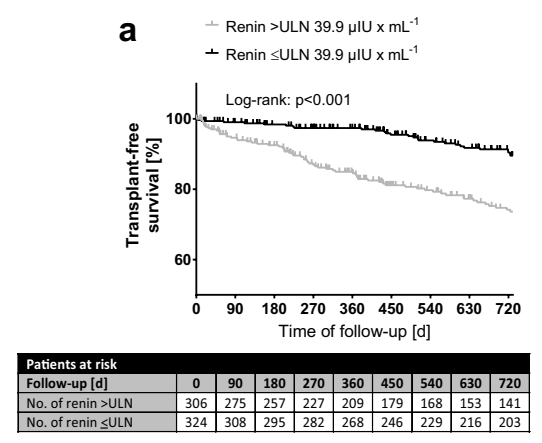

b $\quad+$ proBNP > ULN $125.0 \mathrm{pg} \mathrm{x} \mathrm{mL}^{-1}$

b

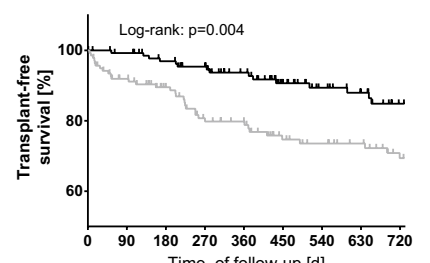

Time of follow-up [d]

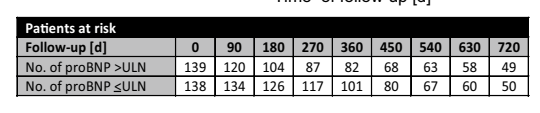

C $\quad+$ Copeptin $>$ ULN $11.4 \mathrm{pmol} \mathrm{x} \mathrm{L-1}$

Log-rank: $p=0.006$

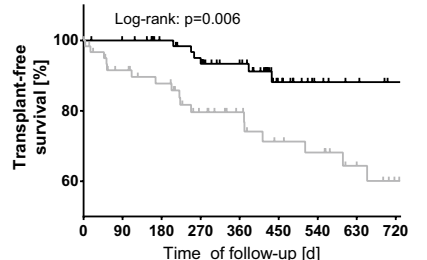
Time of follow-up [d]

\section{CACLD}

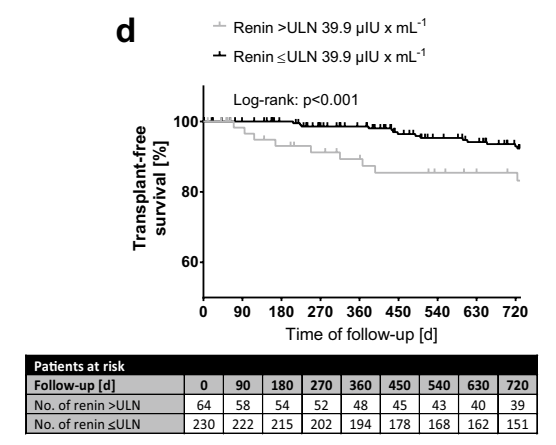

e $\quad+$ proBNP > ULN $125.0 \mathrm{pg} \mathrm{x} \mathrm{mL}^{-1}$

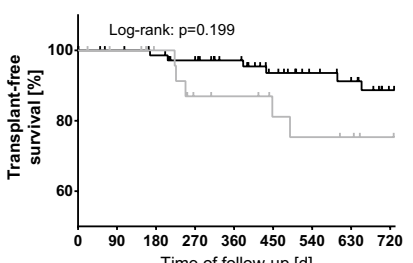

Time of follow-up [d]

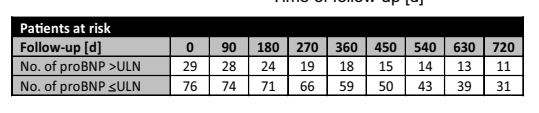

f $\quad+$ Copeptin $>$ ULN $11.4 \mathrm{pmol} \times \mathrm{LL}^{-1}$
- Copeptin $\leq \mathrm{ULN} 11.4 \mathrm{pmol} \times \mathrm{LL}^{-1}$

Log-rank: $p=0.225$

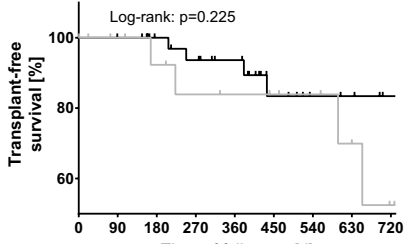

Time of follow-up [d]

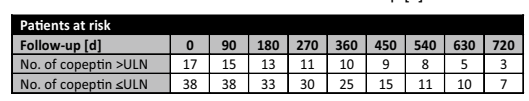

\section{dACLD}

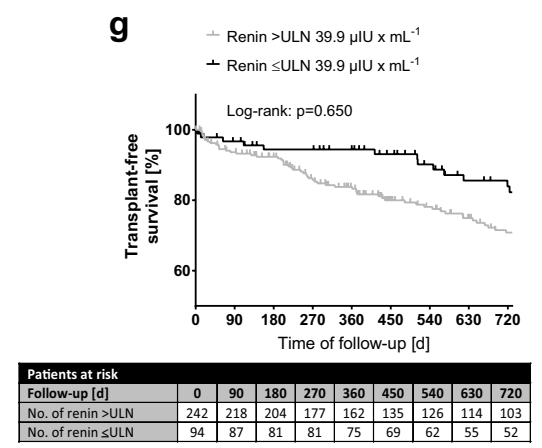

h

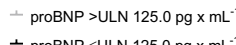

Log-rank: $p=0.137$

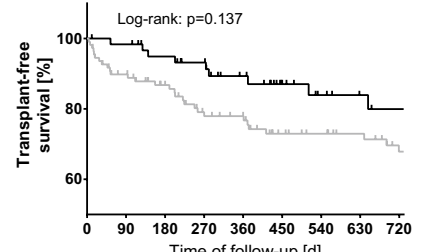

Time of follow-up [d]

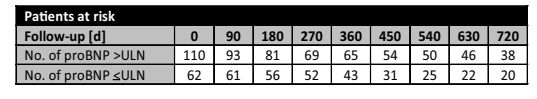

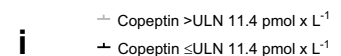

Log-rank: p=0.009

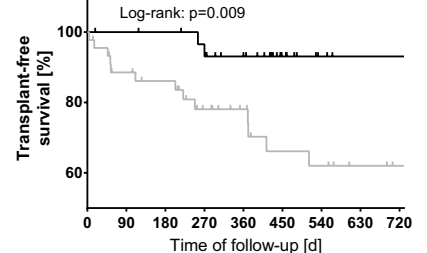

Time of follow-up [d]

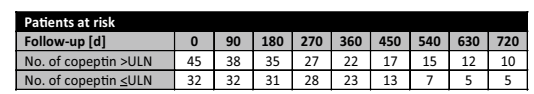

Fig. 3 a-c Transplant-free mortality in ACLD binary for elevated/ non-elevated renin, proBNP and copeptin plasma levels. Transplantfree mortality in d-f cACLD patients and in g-i dACLD patients.

of proBNP levels and heart failure in our cohort, as well as a recent study reporting increased risk for post-TIPS heart failure in patients with elevated BNP levels [30].

\section{Copeptin}

Copeptin was negatively associated with serum sodium concentration, indicating an inadequate activation of AVP in ACLD similar to the syndrome of inappropriate antidiuretic hormone secretion (SIADH) [31], causing additional water retention and worsening of dilutional hyponatremia. This hypothesis is in line with our finding of increased copeptin levels in hyponatremic ACLD patients. The activation of AVP in hyperdynamic portal hypertensive patients likely indicates progressive worsening of the hemodynamic state,
Time to death, liver transplantation or end of follow-up. Log-rank test is used to determine differences between the groups. proBNP probrain-type natriuretic peptide, $U L N$ upper limit of normal as previous studies have reported that plasma copeptin may be a surrogate marker for hemodynamic derangement and worse prognosis in patients with ACLD [18, 32]. In our cohort, elevated copeptin levels were linked to shorter time to first hepatic decompensation in CACLD patients, but failed to reach statistical significance on multivariate analysis, potentially due to the small sample size of this subgroup. Moreover, elevated plasma copeptin levels were independently associated with increased mortality in dACLD patients and in the overall ACLD cohort.

\section{Limitations}

A limitation of this study is that proBNP and copeptin were not evaluated in all patients and thus, duration of follow-up 


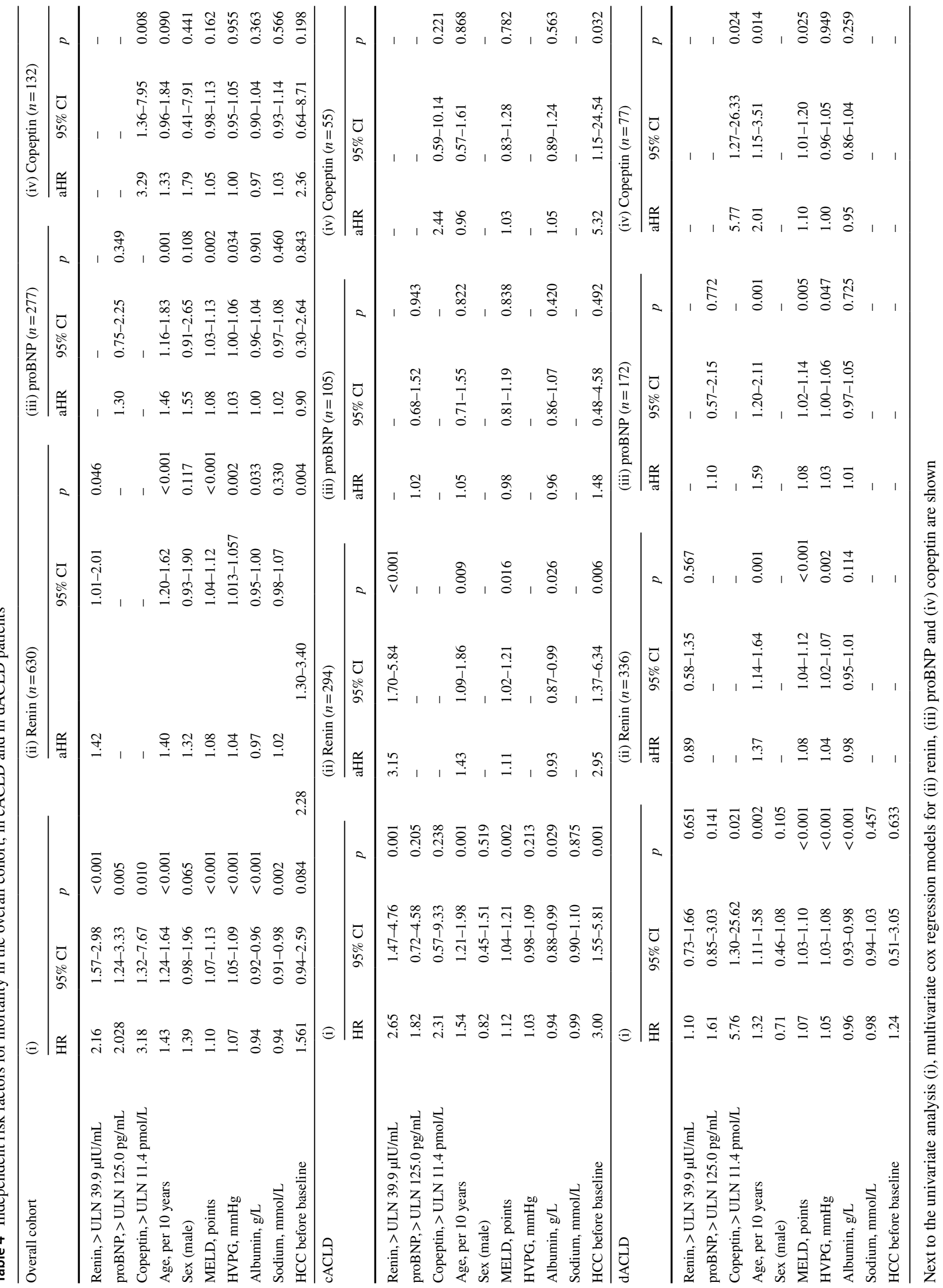


was not similar for the different outcome analyses. Additionally, a single assessment of cardiovascular hormones has limitations and is to be seen as additional tool for risk stratification, rather than replacement of HVPG measurement. Moreover, for copeptin, sample size was limited. Intake of diuretics and angiotensin-converting-enzyme inhibitors/ angiotensin-1-receptor blockers (ACEi/ARB) was unequally distributed throughout the strata of $\mathrm{PH}$ and hepatic dysfunction, as patients with ascites are usually treated with diuretics, while ACEi/ARB are discontinued due to the risk of acute kidney injury. Importantly, proBNP and copeptin levels were not influenced by the intake of diuretics or ACEi/ ARB. However, renin levels correlated with diuretic treatment, which was not routinely discontinued before HVPG measurement and blood withdrawal. Of note, no patient was treated with AVP analogues.

\section{Conclusions}

Our results demonstrate a differential activation of renin, natriuretic proBNP and AVP as critical hormones of circulatory homeostasis across distinct stages of $\mathrm{PH}$ in patients with ACLD. Increased renin levels predict first decompensation and mortality in ACLD and especially cACLD patients, while elevated copeptin levels were independently associated with mortality, in particular in dACLD patients. Future studies should investigate if these biomarkers may identify ACLD patients who benefit from specific therapeutic interventions that target the molecular signaling axis of these cardiovascular hormones.

Supplementary Information The online version contains supplementary material available at https://doi.org/10.1007/s12072-021-10203-9.

Author contributions All authors contributed either to research design (LH, MM and TR) and/or the acquisition (LH, MJ, DS, CD, BS, RP, $\mathrm{EE}, \mathrm{TR}$ ), analysis (LH, MJ, MM, TR) or interpretation (all authors) of data. LH, MM and TR drafted the manuscript, which was critically revised by all other authors.

Funding Open access funding provided by Medical University of Vienna. This study was supported by a Gilead International Liver Disease Research Scholarship (2018-FA716E0930) to T.R.

Data availability All authors have access to the entirety of the data underlying this manuscript. Access to the data can be granted at any time upon reasonable request.

\section{Declarations}

Conflict of interest L.H., M.J., C.D., D.S., R.P., G.S., E.E., R.M., T.S. and S.K. declare no conflict of interest. B.Simbrunner received travel support from AbbVie and Gilead. P.S. received speaking honoraria from Bristol-Myers Squibb and Boehringer-Ingelheim, consulting fees from PharmaIN, and travel support from Falk. D.B. has received travel support from AbbVie and Gilead. B.Scheiner received travel support from Gilead, AbbVie and Ipsen. T.B. received travel support from AbbVie, Bristol-Myers Squibb, and Medis, as well as speaker fees from Bristol-Myers Squibb. M.P.-R. served as investigator for Abbott, Arqle-Daiichi, Bayer, BMS, Boehringer-Ingelheim, Gilead, Imclone, Ipsen, Novartis and Roche, as a speaker and/or advisor for Abbott, Bayer, BMS, Boehringer-Ingelheim, Eisai, Gilead, Ipsen, MSD and Roche, received grant support from Abbott, Bayer, Gilead, MSD and Roche; data and safety monitoring board: BMS, Lilly-Imclone, ONXEO. M.T. received grant support from Albireo, Cymabay, Falk, Gilead, Intercept, MSD, and Takeda, honoraria for consulting from Albireo, Boehringer Ingelheim, BiomX, Falk, Genfit, Gilead, Intercept, MSD, Novartis, Phenex, and 3Regulus, speaker fees from Bristol-Myers Squibb, Falk, Gilead, Intercept and MSD, as well as travel support from AbbVie, FalkGilead and Intercept. M.M. served as a speaker and/or consultant and/or advisory board member for AbbVie, Bristol-Myers Squibb, Gilead, and W. L. Gore \& Associates and received travel support from AbbVie, Bristol-Myers Squibb, and Gilead. T.R. received grant support from AbbVie, Boehringer-Ingelheim, Gilead, MSD, Philips Healthcare, Gore; speaking honoraria from AbbVie, Gilead, Gore, Intercept, Roche, MSD; consulting/advisory board fee from AbbVie, Bayer, Boehringer-Ingelheim, Gilead, Intercept, MSD, Siemens; and travel support from Boehringer-Ingelheim, Gilead and Roche.

Ethical approval The study was approved by the ethics committee (EC) of the Medical University of Vienna (1493/2016) and performed according to the current version of the Helsinki Declaration. Due to the retrospective design of the study the $\mathrm{EC}$ waived the need for informed consent.

Open Access This article is licensed under a Creative Commons Attribution 4.0 International License, which permits use, sharing, adaptation, distribution and reproduction in any medium or format, as long as you give appropriate credit to the original author(s) and the source, provide a link to the Creative Commons licence, and indicate if changes were made. The images or other third party material in this article are included in the article's Creative Commons licence, unless indicated otherwise in a credit line to the material. If material is not included in the article's Creative Commons licence and your intended use is not permitted by statutory regulation or exceeds the permitted use, you will need to obtain permission directly from the copyright holder. To view a copy of this licence, visit http://creativecommons.org/licenses/by/4.0/.

\section{References}

1. Rowe IA. Lessons from epidemiology: the burden of liver disease. Dig Dis. 2017;35(4):304-9.

2. Ripoll C, Groszmann R, Garcia-Tsao G, Grace N, Burroughs A, Planas R, et al. Hepatic venous pressure gradient predicts clinical decompensation in patients with compensated cirrhosis. Gastroenterology. 2007;133(2):481-8.

3. Simbrunner B, Mandorfer M, Trauner M, Reiberger T. Gut-liver axis signaling in portal hypertension. World J Gastroenterol. 2019;25(39):5897-917.

4. Reiberger T, Bucsics T, Paternostro R, Pfisterer N, Riedl F, Mandorfer M. Small esophageal varices in patients with cirrhosisshould we treat them? Curr Hepatol Rep. 2018;17(4):301-15.

5. Garcia-Tsao G, Bosch J. Management of varices and variceal hemorrhage in cirrhosis. N Engl J Med. 2010;362(9):823-32.

6. Berzigotti A, Rossi V, Tiani C, Pierpaoli L, Zappoli P, Riili A, et al. Prognostic value of a single HVPG measurement and Doppler-ultrasound evaluation in patients with cirrhosis and portal hypertension. J Gastroenterol. 2011;46(5):687-95. 
7. Wiest R, Groszmann RJ. The paradox of nitric oxide in cirrhosis and portal hypertension: too much, not enough. Hepatology. 2002;35(2):478-91.

8. Colombato LA, Albillos A, Groszmann RJ. Temporal relationship of peripheral vasodilatation, plasma volume expansion and the hyperdynamic circulatory state in portal-hypertensive rats. Hepatology. 1992;15(2):323-8.

9. Gines P, Guevara M. Hyponatremia in cirrhosis: pathogenesis, clinical significance, and management. Hepatology. 2008;48(3):1002-10.

10. Maslennikov R, Driga A, Ivashkin K, Ivashkin V. NT-proBNP as a biomarker for hyperdynamic circulation in decompensated cirrhosis. Gastroenterol Hepatol Bed Bench. 2018;11(4):325-32.

11. Shim KY, Eom YW, Kim MY, Kang SH, Baik SK. Role of the renin-angiotensin system in hepatic fibrosis and portal hypertension. Korean J Intern Med. 2018;33(3):453-61.

12. Schrier RW, Berl T, Anderson RJ. Osmotic and nonosmotic control of vasopressin release. Am J Physiol. 1979;236(4):F321-32.

13. Nakagawa Y, Nishikimi T, Kuwahara K. Atrial and brain natriuretic peptides: hormones secreted from the heart. Peptides. 2019;111:18-25.

14. Kurtz A. Control of renin synthesis and secretion. Am J Hypertens. 2012;25(8):839-47.

15. Bosch J, Arroyo V, Betriu A, Mas A, Carrilho F, Rivera F, et al. Hepatic hemodynamics and the renin-angiotensin-aldosterone system in cirrhosis. Gastroenterology. 1980;78(1):92-9.

16. Kuiper JJ, Boomsma F, van Buren H, de Man R, Danser AH, van den Meiracker AH. Components of the renin-angiotensinaldosterone system in plasma and ascites in hepatic cirrhosis. Eur J Clin Investig. 2008;38(12):939-44.

17. Paternostro R, Reiberger T, Mandorfer M, Schwarzer R, Schwabl P, Bota S, et al. Plasma renin concentration represents an independent risk factor for mortality and is associated with liver dysfunction in patients with cirrhosis. J Gastroenterol Hepatol. 2017;32(1):184-90.

18. Kerbert AJ, Weil D, Verspaget HW, Moreno JP, van Hoek $\mathrm{B}$, Cervoni JP, et al. Copeptin is an independent prognostic factor for transplant-free survival in cirrhosis. Liver Int. 2016;36(4):530-7.

19. Henriksen JH, Gotze JP, Fuglsang S, Christensen E, Bendtsen $\mathrm{F}$, Moller S. Increased circulating pro-brain natriuretic peptide (proBNP) and brain natriuretic peptide (BNP) in patients with cirrhosis: relation to cardiovascular dysfunction and severity of disease. Gut. 2003;52(10):1511-7.

20. Arroyo V, Bosch J, Gaya-Beltrán J, Kravetz D, Estrada L, Rivera $F$, et al. Plasma renin activity and urinary sodium excretion as prognostic indicators in nonazotemic cirrhosis with ascites. Ann Intern Med. 1981;94(2):198-201.

21. Sansoe G, Aragno M, Wong F. Pathways of hepatic and renal damage through non-classical activation of the renin-angiotensin system in chronic liver disease. Liver Int. 2020;40(1):18-31.
22. Wang LK, An XF, Wu XL, Zhang SM, Yang RM, Han C, et al. Doppler myocardial performance index combined with plasma B-type natriuretic peptide levels as a marker of cardiac function in patients with decompensated cirrhosis. Medicine. 2018;97(48):e13302.

23. Mandorfer M, Kozbial K, Schwabl P, Chromy D, Semmler G, Stattermayer AF, et al. Changes in hepatic venous pressure gradient predict hepatic decompensation in patients who achieved sustained virologic response to interferon-free therapy. Hepatology. 2020;71(3):1023-36.

24. Kulkarni AV, Kumar P, Sharma M, Sowmya TR, Talukdar R, Rao PN, et al. Pathophysiology and prevention of paracentesisinduced circulatory dysfunction: a concise review. J Clin Transl Hepatol. 2020;8(1):42-8.

25. Schepke M, Wiest R, Flacke S, Heller J, Stoffel-Wagner B, Herold T, et al. Irbesartan plus low-dose propranolol versus low-dose propranolol alone in cirrhosis: a placebo-controlled, double-blind study. Am J Gastroenterol. 2008;103(5):1152-8.

26. Tandon P, Abraldes JG, Berzigotti A, Garcia-Pagan JC, Bosch J. Renin-angiotensin-aldosterone inhibitors in the reduction of portal pressure: a systematic review and meta-analysis. J Hepatol. 2010;53(2):273-82.

27. De BK, Bandyopadhyay K, Das TK, Das D, Biswas PK, Majumdar D, et al. Portal pressure response to losartan compared with propranolol in patients with cirrhosis. Am J Gastroenterol. 2003;98(6):1371-6.

28. Papakrivopoulou E, Lillywhite S, Davenport A. Is N-terminal probrain-type natriuretic peptide a clinically useful biomarker of volume overload in peritoneal dialysis patients? Nephrol Dial Transplant. 2012;27(1):396-401.

29. Izzy M, VanWagner LB, Lin G, Altieri M, Findlay JY, Oh JK, et al. Redefining cirrhotic cardiomyopathy for the modern era. Hepatology. 2020;71(1):334-45.

30. Billey C, Billet S, Robic MA, Cognet T, Guillaume M, Vinel JP, et al. A prospective study identifying predictive factors of cardiac decompensation after transjugular intrahepatic portosystemic shunt: the Toulouse algorithm. Hepatology. 2019;70(6):1928-41.

31. Peri A, Pirozzi N, Parenti G, Festuccia F, Mene P. Hyponatremia and the syndrome of inappropriate secretion of antidiuretic hormone (SIADH). J Endocrinol Investig. 2010;33(9):671-82.

32. Kerbert AJ, Verbeke L, Chiang FW, Laleman W, van der Reijden JJ, van Duijn W, et al. Copeptin as an indicator of hemodynamic derangement and prognosis in liver cirrhosis. PLoS ONE. 2015;10(9):e0138264.

Publisher's Note Springer Nature remains neutral with regard to jurisdictional claims in published maps and institutional affiliations.

\section{Authors and Affiliations}

\section{Lukas Hartl $^{1,2}$ - Mathias Jachs ${ }^{1,2}$. Christopher Desbalmes ${ }^{1,2}$. Dunja Schaufler ${ }^{1,2} \cdot$ Benedikt Simbrunner $^{1,2,3}$. Rafael Paternostro ${ }^{1,2}$. Philipp Schwabl ${ }^{1,2,3}$. David Josef Maria Bauer ${ }^{1,2}$. Georg Semmler ${ }^{1,2}$. Bernhard Scheiner ${ }^{1,2}$. Theresa Bucsics $^{1,2}$. Ernst Eigenbauer ${ }^{4} \cdot$ Rodrig Marculescu $^{5} \cdot$ Thomas Szekeres $^{5}$ - Markus Peck-Radosavljevic ${ }^{1,2,6}$. Stefan Kastl ${ }^{7} \cdot$ Michael Trauner $^{1} \cdot$ Mattias Mandorfer ${ }^{1,2} \cdot$ Thomas Reiberger $^{1,2,3}$ (i)}

Lukas Hartl

lukas.a.hartl@meduniwien.ac.at

Mathias Jachs

mathias.jachs@meduniwien.ac.at
Christopher Desbalmes

c.desbalmes@hotmail.com

Dunja Schaufler

dunja.schaufler@sce-schaufler.at 
Benedikt Simbrunner

benedikt.simbrunner@meduniwien.ac.at

Rafael Paternostro

rafael.paternostro@meduniwien.ac.at

Philipp Schwabl

philipp.schwabl@meduniwien.ac.at

David Josef Maria Bauer

david.bauer@meduniwien.ac.at

Georg Semmler

georg.semmler@meduniwien.ac.at

Bernhard Scheiner

bernhard.scheiner@meduniwien.ac.at

Theresa Bucsics

theresa.bucsics@meduniwien.ac.at

Ernst Eigenbauer

ernst.eigenbauer@meduniwien.ac.at

Rodrig Marculescu

rodrig.marculescu@meduniwien.ac.at

Thomas Szekeres

thomas.szekeres@meduniwien.ac.at

Markus Peck-Radosavljevic

markus@peck.at

Stefan Kastl

stefan.kastl@meduniwien.ac.at
Michael Trauner

michael.trauner@meduniwien.ac.at

Mattias Mandorfer

mattias.mandorfer@meduniwien.ac.at

1 Division of Gastroenterology and Hepatology, Department of Medicine III, Medical University of Vienna, Waehringer Guertel 18-20, 1090 Vienna, Austria

2 Vienna Hepatic Hemodynamic Lab, Medical University of Vienna, Vienna, Austria

3 Christian Doppler Lab for Portal Hypertension and Liver Fibrosis, Medical University of Vienna, Vienna, Austria

4 IT-Systems and Communications, Medical University of Vienna, Vienna, Austria

5 Department of Laboratory Medicine, Medical University of Vienna, Vienna, Austria

6 Department of Internal Medicine and Gastroenterology (IMuG), Hepatology, Endocrinology, Rheumatology and Nephrology, Central Emergency Medicine (ZAE), Klinikum Klagenfurt am Wörthersee, Klagenfurt, Austria

7 Division of Cardiology, Department of Medicine II, Medical University of Vienna, Vienna, Austria 